UDC 32:001.8+37

Submitted: 07.06.2018

LBC $66.01+74$

Accepted: 09.07.2018

\title{
EDUCATION AS A SOFT POWER IN MODERN FOREIGN AND RUSSIAN POLITOLOGICAL RESEARCH
}

\author{
Ekaterina A. Antyukhova \\ Moscow State Institute of International Relations, Ministry of Foreign Affairs of Russia, \\ Moscow, Russian Federation
}

\begin{abstract}
In the modern world education plays an important role traditionally acting as an institution of knowledge transfer. At the same time, under the conditions of the multipolar world the role of education has considerably expanded. It is ingrained in the foreign policy arsenal of a number of states, being the integral part and form of their foreign policy strategy.

The paper deals with the approaches of a number of Russian and foreign political scientists to the problem of qualifying education as one of the tools of the soft power policy. This topic doesn't yet occupy the sufficient place in domestic politological research that is conditioned by the fact that Russia has adopted the concept of soft power as a true instrument of political influence in the international field with some delay.

Speaking about the geography of the research, it should be noted that western authors take interest in various regions of the world and, first of all, in the most actively developing states such as, for example, China. As for Russian works, in most cases they are devoted either to the analysis of the domestic experience of implementing the policy of soft power with the use of the resource of education, or to the European policy in the context of the participation of the Russian Federation in Bologna Process. All these fact allow for concluding that the problem under consideration demands further studying and conceptualization.

Key words: education, higher education, soft power, international relations, diplomacy of knowledge, universities, education internationalization.

Citation. Antyukhova E.A. Education as a Soft Power in Modern Foreign and Russian Politological Research. Vestnik Volgogradskogo gosudarstvennogo universiteta. Seriya 4, Istoriya. Regionovedenie. Mezhdunarodnye otnosheniya [Science Journal of Volgograd State University. History. Area Studies. International Relations], 2018, vol. 23, no. 4, pp. 197-209. (in Russian). DOI: https://doi.org/10.15688/jvolsu4.2018.4.17
\end{abstract}

УДК $32: 001.8+37$

ББК $66.01+74$

Дата поступления статьи: 07.06.2018

Дата принятия статьи: 09.07.2018

\section{ОБРАЗОВАНИЕ КАК «МЯГКАЯ СИЛА» В СОВРЕМЕННЫХ ЗАРУБЕЖНЫХ И РОССИЙСКИХ ПОЛИТОЛОГИЧЕСКИХ ИССЛЕДОВАНИЯХ}

\author{
Екатерина Андреевна Антюхова \\ Московский государственный институт международных отношений (У) МИД РФ, \\ г. Москва, Российская Федерация
}

\footnotetext{
Аннотация. В современном мире образование играет важную роль, традиционно выступая в качестве института передачи знаний. Вместе с тем, в условиях многополярного мира роль образования значительно расширилась. Оно прочно входит во внешнеполитический арсенал целого ряда государств, являясь неотьемлемой составляющей и формой их внешнеполитической стратегии.

В статье рассмотрены подходы ряда российских и зарубежных политологов к проблеме определения образования в качестве одного из инструментов политики «мягкой силы». Данная проблематика еще не занимает достаточного места в отечественных политологических исследованиях. Это обусловлено тем, что Россия с некоторым опозданием восприняла концепцию «мягкой силы» в качестве реального инструмента

политического влияния на международной арене.
} 


\section{ПОЛИТИЧЕСКИЕ НАУКИ И РЕГИОНОВЕДЕНИЕ}

Говоря о географии исследований, следует отметить, что западные авторы проявляют интерес к различным регионам мира и в первую очередь к наиболее активно развивающимся государствам, таким как, например, Китай. Российские же работы в основе своей посвящены либо анализу отечественного опыта по реализации политики «мягкой силы» с использованием ресурса образования, либо европейской политике в контексте участия Российской Федерации в Болонском процессе. Все это говорит о том, что рассматриваемая проблема требует дальнейшего изучения и концептуализации.

Ключевые слова: образование, высшее образование, «мягкая сила», soft power, международные отношения, дипломатия знаний, университеты, интернационализация образования.

Цитирование. Антюхова Е. А. Образование как «мягкая сила» в современных зарубежных и российских политологических исследованиях // Вестник Волгоградского государственного университета. Серия 4, История. Регионоведение. Международные отношения. -2018. - Т. 23, № 4. - С. 197-209. - DOI: https://doi.org/ 10.15688/jvolsu4.2018.4.17

\section{Введение}

Категория «мягкая сила» уже не первый год активно используется политологами для определения новой системы международного влияния и достижения национальных интересов. В современной российской и зарубежной политической науке накоплен определенный опыт исследований, посвященных непосредственно феномену «мягкой силы», как нового инструмента международных отношений. Тем не менее отдельные положения все еще требуют самого тщательного анализа и осмысления. Это касается как теоретических аспектов рассматриваемого феномена, так и выявления инструментов реализации «мягкой силы» в практической плоскости.

Безусловно, «мягкая сила» сегодня остается все еще крайне спорным политологическим концептом, учитывая, что традиционные силовые методы и формы разрешения противоречий на международной арене не только не отходят на задний план, но, напротив, активно используются в решении тех или иных вопросов.

Таким образом, правильнее было бы говорить о некоем симбиозе «жесткой» и «мягкой» силы, так как они представляют собой два аспекта достижения одной и той же цели способность достичь своего путем влияния на поведение других [41, p. 7].

«Мягкая сила» постепенно занимает свое место в теории и практике современных международных отношений, что, несомненно, требует ее тщательного анализа и рассмотрения. Особую же важность и актуальность проблема определения и применения инструментов «мягкой силы» приобретает в свете того, что с 2013 г. данное понятие используется в официальных документах Российской Федерации. В действующей редакции «Концепции внешней политики Российской Федерации» отмечается, что «неотъемлемой составляющей современной международной политики становится использование для решения внешнеполитических задач инструментов “мягкой силы", прежде всего возможностей гражданского общества, информационно-коммуникационных, гуманитарных и других методов и технологий, в дополнение к традиционным дипломатическим методам» [6].

\section{Методология}

Образование понимается сегодня как один из «подвидов» $[47$, с. 46] «мягкой силы», что находит свое отражение в соответствующих рейтингах «мягкой силы» государств.

Первый подобный рейтинг появился в 2010 г. (The New Persuaders: An international ranking of soft power), последний - в 2017 г. (The Soft Power 30. A Global Ranking of Soft Power). Тем не менее конкретное содержание категории «мягкая сила» все еще является достаточно дискуссионным как с теоретической, так и с практической точки зрения. Если в случае с теоретическим аспектом мы говорим о дискуссиях вокруг возможности понимая «силы» в принципе, в ее неклассической трактовке (то есть не как hard power) и противопоставлении «мягкой силе» категории «дипломатия» как традиционного несилового инструмента международных отношений, то в практической плоскости, при принятии со стороны части научного сообщества самого концепта «мягкой силы», - о формах и методах ее реализации. 
Как известно, сам Дж. Най в своих работах выделял несколько основных механизмов/инструментов «мягкой силы», которые, с его точки зрения, являются наиболее действенными и эффективными: культурная привлекательность (культура), идеологическая привлекательность (идеология), привлекательная внутренняя политика, привлекательная внешняя политика [39; 40; 41$]$.

Дж. Най выделил основные смысловые блоки, которые, безусловно, требовали и требуют своего уточнения и расшифровки. В связи с этим в политической науке продолжается дискуссия о конкретных инструментах реализации «мягкой силы». Российские авторы выделяют среди них следующие: репутационный менеджмент и информационные войны (Е. Широкова) [23], информационно-коммуникативные технологии и информация (А.А. Миронов, В. Капицын) [12; 4], теория международных отношений как научная дисциплина, способная влиять на сознание политической общественности (А.П. Цыганков) [20], идеология и институты (И.В. Радиков, Я.В. Лексютина) [15], политический пиар, глобальный маркетинг, публичная дипломатия, туризм, спорт и культурные обмены, система образования и студенческие обмены, миграционная политика, национальные диаспоры, культура (О.Г. Леонова) [11], СМИ, медиапродукция, культурные проекты, международные образовательные программы (Е.П. Панова) [13].

Образование, как один из возможных (и необходимых) инструментов «мягкой силы», указывается также в работах таких российских исследователей, как А.В Торкунов, М.М. Лебедева и др. [18; 9].

В частности, М.М. Лебедева, рассуждая о евразийской интеграции, пишет: «Представляется, что именно наука и образование позволит России углубить евразийскую интеграцию, преодолеть возникающее порой недоверие со стороны ее соседей, направить позитивный опыт интеграции в экономической области на смежные сферы межгосударственных взаимодействий на постсоветском пространстве» [10].

Важно упомянуть о том, что концептуально роль образования как инструмента «мягкой силы» в западной политической науке во многом было обосновано исследова- тельницей Д. Найт, которая активно развивает и расширяет идеи Дж. Ная. Д. Найт исходит в первую очередь из того, что на сегодняшний день, согласно ее мнению, произошли серьезные изменения роли традиционной дипломатии на мировой арене. Дипломатия традиционно интерпретируемая как область государственного управления международными отношениями в лице министерств иностранных дел, постепенно трансформируется в многонаправленный процесс со множеством акторов. Мультиактивный подход является отличительной чертой современной дипломатии. Не только широкий спектр правительственных учреждений становится ключевым игроком в дипломатических отношениях, но и многочисленные организации гражданского общества, транснациональные корпорации и сети экспертов признаются важными агентами в управлении международными связи. В результате высшее образование в форме национальных и региональных ассоциаций, университетов и колледжей, студентов и преподавателей, экспертных сетей, фондов и правительственных учреждений является на сегодняшний день также одним из субъектов, активно занимающихся международными отношениями [36, p. 2].

Д. Найт ставит довольно важный вопрос: можно ли в принципе считать образование элементом/инструментом «мягкой силы»? Анализируя различные международные образовательные программы (Фулбрайт, программы Британского Совета, Эрасмус и другие), она отмечает, что все они способствуют обмену студентами, знаниями, компетенциями, то есть имеют, казалось бы, взаимовыгодный характер. Так можно ли их в таком случае считать инструментами влияния? Д. Найт отмечает, что «международное высшее образование традиционно не считается игрой победителей и проигравших - оно ориентировано на обмен и партнерство и основывается на сильных сторонах стран/высших учебных заведений и научно-исследовательских учреждений. Кроме того, оно дает решения и преимущества для всех игроков, заранее признающих, что выгоды будут отличаться среди участников процесса» [36, p. 2].

Данный парадокс, в котором возник, с точки зрения Д. Найт, непреодолимый дуа- 
лизм между «силой» и «взаимной выгодой», привел ее к мысли о том, что сегодня адекватной силовой парадигмой (даже в формате «мягкой силы») является дипломатическая парадигма. И в этом контексте образование должно являться продолжением дипломатии, а не каких-либо силовых концептов. В результате, Д. Найт предлагает новую концепцию «дипломатии знаний» (knowledge diplomacy), соответствующей формирующейся экономике знаний [35, p. 8-9].

Таким образом, мы можем констатировать, что в западной политической науке на сегодняшний день сформировалось два ключевых подхода к месту и роли образования на международной арене. Как отмечает в связи с этим А.А. Габриелян, «вызовом в системе высшего образования является проблема использования идеи «мягкой силы» или ее более гуманной альтернативы - мягкой силы с взаимным эффектом» [2].

\section{Анализ}

Итак, с точки зрения отечественных авторов, образование следует рассматривать в его различных аспектах в качестве одного из инструментов «мягкой силы». Схожей позиции придерживается и целый ряд зарубежных исследователей. Так, как отмечает А. Амирбек, «в настоящее время растет число стран, которые считают образование наилучшим способом продвижения своих национальных интересов на мировой арене» [24, p. 514-516].

Польские исследователи А. Войчук и М. Михалек указывают на тот факт, что ключевой тенденцией развития современного образования является его активная интернационализация. В связи с этим, использование «мягкой силы» образования становится крайне актуальным направлением. Следует отметить, что указанные авторы предлагают в своей статье и теоретическую концептуализацию «мягкой силы» образования, выявляя три механизма, с помощью которых она может эффективно работать: как носитель подлинных ценностей, как ресурс, которым обладают страны, и как инструмент достижения определенных целей. По мнению А. Войчук и М. Михалека, все три механизма показывают, как растущая интернационализация ведет ко все более прямым связям между образованием, международными отношениями и внешней политикой [50].

Важность фактора интернационализации образования в контексте расширения возможностей для продвижения своих национальных интересов отмечают и В. Куприянова-Ашина и Чанг Жу (Свободный университет Брюсселя, Бельгия): «Интернационализация высшего образования может осуществляться с целью распространения собственных ценностей и формирования позитивного образа страны» [7, с. 87-88].

Зарубежные авторы подчеркивают тот немаловажный факт, что вряд ли можно говорить об образовании как «мягкой силе», выступающей неким новейшим феноменом в международных отношениях. Так, В. Томуск пишет о том, что в ходе человеческой истории «образование не раз было как оружие для того, чтобы завоевать сердца и умы противников...» [49, p. 227-249]. В связи с этим М.Р. Ботонеро указывает, что исторические корни использования образования в достижении внешнеполитических целей требуют «пересмотра понятия “мягкая сила", разработанного Дж. Наем, и, в частности, в плане рассмотрения высшего образования как источника “мягкой силы"» [27, p. 2]. Отметим, что схожей позиции по данному вопросу придерживается и ряд российских исследователей. В частности, А.В. Торкунов прямо пишет о том, что «Советский Союз долгое время успешно использовал высшее образование в качестве инструмента геополитики и «идеологического оружия» в условиях блокового противостояния и холодной войны еще задолго до возникновения самого понятия «мягкой силы»»» [18, с. 88-89].

Следует отметить, что если современные отечественные исследования в области анализа использования образования в качестве инструмента «мягкой силы» сосредоточены, как правило, либо на самой России, либо на Европейском союзе (что, видимо, объясняется участием России в Болонском процессе), то на западе политическая наука все больше обращается к анализу китайского опыта.

Как быстро развивающаяся мировая держава, Китай, безусловно, привлекает исследовательское внимание, в том числе и с 
точки зрения использования им инструментов «мягкой силы». По мнению западных исследователей, Китай сегодня все больше использует образование в этом направлении. Как отмечает Э. Метцгар, глобальное присутствие Китая стало важной темой и, тем не менее, все еще крайне мало внимания со стороны исследователей было уделено роли высшего образования в проектировании «мягкой силы» Китая [37, p. 223-241]. Схожего мнения придерживается и К. Кинг, Р. Янг и другие авторы [28; 29; 52, р. 235-245; 53]. В частности, Р. Янг пишет: «Соразмерно с подъемом Китая как экономической и политической силы наблюдался рост китайской мягкой силы... Высшее образование было в центре внимания в Китае в качестве наиболее систематически планируемого элемента политики мягкой силы» [51, p. 24].

В 2009 г. в свет вышла коллективная монография «Китайская мягкая сила и ее влияние на Соединенные штаты», авторы которой (Дж. Алтерман, К. Блисс, Э. Чоу, Дж. Кук, С. Фланаган, Б. Глэйзер и др.) рассмотрели различные аспекты, в том числе и образовательный, использования Китаем потенциала мягкой силы в таких регионах мира как Африка, Ближний и Средний Восток, Латинская Америка, Азия. Данное исследование со всей очевидностью подтвердило, что Китай сегодня проводит крайне активную международную образовательную политику, целью которой является усиление его влияния в важных для него геополитических регионах [30].

Кроме этого, западные исследователи акцентируют свое внимание на восточноевропейском политическом векторе, анализируя возможности образования как «мягкой силы» на данном направлении, в том числе, и на постсоветском пространстве. Так, Г. Полглас анализирует применение образовательной «мягкой силы» в Беларуси, делая вывод о том, что через систему высшего образования «ЕС продемонстрировал значительные рычаги влияния мягкой силы путем продвижения своей культуры, политических ценностей и внешней политики в странах Восточного партнерства» [44, p. 120]. В. Джонс рассматривает возможности ЕС в применении образовательной «мягкой силы» в Юго-Восточной Азии. В качестве основного вывода данный автор высказыва- ет мысль о том, что на сегодняшний день ЕC не в полной мере задействует инструментарий, в том числе и образовательный, по причине институциональной слабости самого Европейского союза [34, p. 65].

Завершая обзор работ западных исследователей по отдельным странам, следует назвать и статью С. Грина, посвященную аспекту «мягкой силы» в образовательной политике Японии [33, p. 89-101].

Говоря о подходах к определению «мягкой силы» и образованию со стороны российских исследователей, отметим, что они опираются, как правило, на анализ отечественного и европейского опыта.

Значительный интерес здесь вызывает исследование, проведенное А.В. Торкуновым, который в своей статье вычленил конкретные направления реализации образовательной политики в контексте понимания ее как «мягкой силы»: экспорт и импорт образования, международная мобильность студентов и преподавателей, борьба за высокие места в престижных международных образовательных рейтингах, интернационализация университетов, увеличение наукометрических показателей [18].

Российский опыт нашел свое отражение в работах М.М. Лебедевой, которая делает важный вывод о том, что в России «на сегодняшний день еще нет четкой программы и комплекса мер, предусматривающих использование высшего образования в этих целях. Можно выделить пока лишь отдельные направления работы» [9, с. 200-205].

Диссертационное исследование В.Д. Агеевой посвящено анализу использования инструментов «мягкой силы» во внешней политике Российской Федерации в контексте глобализации [1]. Несмотря на то, что образование не выделяется в нем в качестве самостоятельного направления исследования, но, тем не менее, косвенно оно затрагивается в работе скорее в теоретическом аспекте.

В общем контексте образование рассматривается и в статье Ю.Н. Саямова [16]. В своей небольшой по объему статье Н.Е. Суханова затрагивает образовательную составляющую внешней политики России, отмечая, что «анализ практического использования инструментария данного феномена показывает, что в российской действительности использование 
возможностей образовательных систем как механизма “мягкой силы” осуществляется недостаточно эффективно как в информационном продвижении заслуг и достижений российской системы образования, так и в слабом информационно-коммуникативном продвижении имиджа российского образования в глазах зарубежной, да и российской общественности» $[17$, с. 83$]$.

Китайский опыт реализации образовательной политики «мягкой силы» нашел отражение в статье Д.М. Ковалевой, которая полагает, что «с точки зрения мягкой силы долгосрочное воздействие, осуществляемое во время образовательного процесса, гораздо эффективнее, нежели краткосрочные пропагандистские кампании» [5, с. 33].

Рассмотрению политики «мягкой силы» Китая в ее образовательном аспекте посвящена и статья М.П. Першиной «Образование как инструмент "мягкой силы" внешней политики Китая». Следует отметить, что данная работа является на сегодня, пожалуй, наиболее полной и раскрывающей особенности китайской образовательной «мягкой силы». Важно отметить, что М.П. Першина в своем анализе исходит из актуальных теоретикометодологических западных подходов, четко разграничивающих «мягкую силу» и «культурную дипломатию». Так, в частности, она пишет следующее: «Сегодня КНР также активно реализует свои амбиции по наращиванию soft power, в том числе стимулируя процессы студенческой мобильности в стране. Все большая значимость при формировании внешнеполитическои стратегии придается "мягкой силе" и культурной дипломатии - действенному инструменту формирования привлекательного образа Китая и китайцев» [14].

Т.А. Ланьшина проанализировала германскую образовательную политику «мягкой силы» с точки зрения организации и финансирования осуществляющих ее государственных и негосударственных институтов. Особый интерес исследование вызывает в связи с тем, что автор рассмотрел и практическую составляющую вопроса - конкретные направления и методы на примере целого ряда государств: Казахстана, Украины, Армении, Азербайджана, Узбекистана, Таджикистана, Киргизии, Монголии, Вьетнама, Бразилии [8].
Европейское измерение образовательной «мягкой силы» рассмотрено в статье М.А. Чепуриной, посвященной Болонскому процессу. Автор указывает, что «Болонский процесс инструмент публичной дипломатии». Подобный подход свидетельствует о том, что в авторской концепции непроводится различий между «мягкой силой» и «дипломатией» [21, с. 100$]$.

Одним из важнейших механизмов сотрудничества в области образования на международной арене является так называемый образовательный обмен. Как отмечает А.В. Долинский, «образовательные обмены являются ключевым элементом публичной дипломатии большинства стран, они считаются эффективными в данной области внешнеполитической деятельности... были и остаются ключевым инструментом публичной дипломатии, направленным на развитие национальной soft power» [3]. В связи с этим значительный интерес представляет анализ такого инструмента образования «мягкой силы» как обменные программы (exchange programs). Сам Дж. Най полагает, что программы культурного и образовательного обмена являются мощнейшим инструментов влияния. Так, рассуждая об интересах США на Среднем Востоке, он писал: «Наиболее важным, однако, будет разработка долгосрочной стратегии культурного и образовательного обмена, которые способствуют развитию более богатого и открытого гражданского общества в государствах Среднего Востока. Наиболее эффективными представителями США там являются не сами американцы, а представители коренного населения, которые понимают добродетели Америки...»[43, p. 122].

Американский опыт в данной сфере анализируется в статье А. Фоминых, который отмечает, что США имеют богатый опыт по реализации подобных программ в целях достижения собственных внешнеполитических целей. При этом автор подчеркивает, что американские «программы взаимного образовательного и культурного обмена» представляют собой институционализированные программы, создаваемые на базе специального федерального закона (Fulbright-Hays Act, 1961) и «проводимые на регулярной основе цикличные мероприятия с возобновляемым бюджетом, регламентированным содержанием и строго очерченной целевой аудиторией» [19, с. 77]. 
Отметим, что на сайте Госдепартамента США недвусмысленно указывается, что американские Программы образовательных и культурных обменов призваны не только способствовать налаживанию «взаимопонимания между людьми», но и формированию у их участников определенных ценностей: свободы, политического представительства, верховенства закона, личного достоинства [32].

Таким образом, автор подчеркивает, что сегодня для России крайне важно актуализировать само понятие «международный обмен», наполнив его реальным политическим содержанием в контексте использования «мягкой силы».

В концептуальных построениях западных авторов международный обмен в формате академической мобильности уже не первый год воспринимается не только как фактор личностного развития, но и как важный социальный инструмент. Так М. Байрем и Ф. Дервин прямо указывают, анализируя европейский опыт, что «политика поощрения академической мобильности студентов в Европе является частью общего намерения по созданию европейского государства особого вида и “европейской идентичности”» [22].

По мнению южнокорейского исследователя Ч. Шенг-Кая, такие государства как Соединенные Штаты, Великобритания и Австралия некоторое время признавали потенциал мягкой силы как различных инициатив в области высшего образования. В результате, многие студенты, обучившиеся за рубежом, «в конечном итоге вернутся в свои страны и займут руководящие должности в государственном и частном секторах» $[45$, p. 3$]$.

Следует отметить, что исследователи выделяют как позитивные, так и негативные стороны международного образовательного обмена. Если сторонники «негативного» подхода видят в нем одностороннее влияние со стороны наиболее сильных государств, обладающих значительным образовательным (и политическим) потенциалом, то с точки зрения сторонников «позитивного» подхода (среди них можно выделить таких авторов, как Дж. Стетар, Дж. Коппла, Р. Шилдс, Р. Эдвардс, П. Альтбак и др.) международный обмен обогащает обе стороны, участвующие в нем.
Так, по мнению Дж. Стетара, обучившиеся за границей студенты, возвращаясь, приносят на родину «перспективу той страны, в которой они проходили обучение» [48]. Р. Шилдс и Р. Эдвардс полагают, что модель современной академической мобильности значительно помогает периферийным государствам [46, р. 237], при этом «принимающие страны могут реализовать цели внешней политики, приобрести дополнительный пул квалифицированной рабочей силы, а другая сторона - приобрести новые навыки и знания» [25, p. 127].

Типичным примером позитивного подхода может служить мнение бразильского исследователя К. Милани, который полагает, что благодаря международной кооперации (в том числе, обмену) в области образования «бразильское правительство действует, по крайней мере, в трех направлениях: 1) с экономической точки зрения образование непосредственно связано с квалификацией рабочей силы и, таким образом, сотрудничество является одной из форм взаимоотношений, которая направлена на создание потенциала в этой сфере; 2) в политическом плане сотрудничество в области образования является частью позитивной повестки дня внешней политики Бразилии, так как оно содействует установлению более тесных отношений между государствами и обществами на основе принципов солидарности и невмешательства во внутренние дела других развивающихся стран; 3) культурное сосуществование, изучение языков и обмен опытом способствует укреплению связей между различными обществами, делая возможным взаимопонимание между странами» [38].

Среди других наиболее важных инструментов «мягкой силы» в формате образования исследователями выделяется роль и место университетов в современном мире. Данная тематика тесно связана с предыдущим аспектом - интернационализацией образования. Интернационализация образования, в целом, предполагает способность стран раскрывать свою внутреннюю культуру, ее привлекательные черты для иностранных студентов. Отметим, что в этом контексте как элемент политики «мягкой силы» крайне важна инициатива России по реализации приоритетного проекта «Развитие экспортного потенциала 


\section{ПОЛИТИЧЕСКИЕ НАУКИ И РЕГИОНОВЕДЕНИЕ}

российской системы образования», рассчитанного на период до 2025 г. и направленного на повышение конкурентоспособности российского образования на международном рынке образовательных услуг.

Как отмечал Дж. Най, «студенты, которые посещают иностранные университеты, обычно возвращаются домой с большим признанием... ценностей и институтов» [42, p. 42].

В связи с этим Э. Деодато и И. Борковска указывают на тот факт, что современная дипломатия все более сильно связана с процессом рыночной глобализации и формированием общества знаний. В этой ситуации высшие учебные заведения начинают ориентироваться на стратегию интернационализации с целью получения определенных рыночных преимуществ. Ключевыми целями становится занятие наиболее выгодной и привлекательной ниши на рынке образовательных услуг. И, по сути, именно этот фактор должен учитываться и в политическом аспекте - государство должно и может использовать университеты в своих политических интересах: «Инструментальная модель, в свою очередь, активно продвигается и сегодня широко представлена: она подразумевает, что университет является инструментом политической повестки дня и имеет миссию решать текущие социальные и экономические вопросы. Влияние правительств и внешних заинтересованных сторон, с одной стороны, и императив научного предпринимательства, с другой, - два основных драйвера этого подхода» [31].

Вторым же вариантом использования данного инструмента является экспорт своих образовательных программ. С этой целью государством сегодня поддерживается процесс интернационализации и стандартизации образовательных программ по международным стандартам. При этом некоторые авторы полагают, что «мягкой силе» университетов мешает излишний государственный контроль. Так, Р. Бертелсен, анализируя роль университетов как «мягкой силы» на Ближнем Востоке, пишет, что в XX в. «мягкой силе университета способствовали государственная финансовая поддержка, но в то же время слишком тесная связь с государством угрожала этой мягкой силой» [26].
Отметим, что по мнению ряда авторов, слишком активное воздействие на чужие системы образования, в том числе путем финансовых инвестиций в зарубежные университеты, является, по сути, одной из форм «неоколониализма»: «Идея о том, что иностранные инвесторы будут постепенно монополизировать национальные системы высшего образования, где недофинансируемые государственные университеты будут бороться за конкурентоспособность - одна из причин того, что либерализация высшего образования воспринимается как угроза во многих странах» [27, p. 11].

\section{Выводы}

Проведенный в статье анализ показал, что тема образования как одного из инструментов реализации «мягкой силы» получает постепенное развитие в современной политической науке в России. Со всей очевидностью можно констатировать тот факт, что отечественные политологи, особенно в последнее время, активно пытаются заполнить тот существенный пробел, который имел место в их трудах при исследовании образования в качестве одного из инструментов политики «мягкой силы». Это связано, на наш взгляд, с тем, что до определенного момента высшее образование в России находилось в состоянии кризиса. А потому российская система образования во многом сама подвергалась воздействию западной «мягкой силы», не имея фактической возможности дать адекватный ответ.

Начавшиеся в 2000-х гг. реформы в системе образования свидетельствуют о том, что и Россия приступила к активному использованию данного инструмента. Именно в этот период наблюдается появление большинства статей российских специалистов по проблеме. При этом большая часть из них была посвящена российской проблематике, и лишь незначительный объем - международной.

Образование выступает сегодня в качестве одного из элементов публичной дипломатии. Наряду с традиционными формами в «борьбе за умы», преимущество влияния на мир через образование вполне очевидно. Неслучайно многие государства мира пытают- 
ся воздействовать на общественное сознание, создавая благоприятный имидж государства, опираясь при этом на продвижение своих национальных ценностей, среди которых, в том числе и экспорт образования. Как показывает практика, «в современном глобальном мире конкуренция приобретает культурно-цивилизационное измерение» $[18$, с. 86$]$. Учитывая изменяющиеся реалии, именно образование способно выступить тем действенным механизмом, который может стать одним из важнейших конкурентных преимуществ России в борьбе за международное лидерство.

В результате, как представляется, реальные политические процессы со временем подтолкнут и исследовательский интерес, что станет причиной появления новых работ российских ученых, посвященных образованию как к одному из важнейших инструментов «мягкой силы».

\section{СПИСОК ЛИТЕРАТУРЫ}

1. Агеева, В. Д. Роль инструментов «мягкой силы» во внешней политике Российской Федерации в контексте глобализации : дис. ... канд. полит. наук : 23.00.04 : защищена 25.11.2016 / Агеева Вера Дмитриевна. - СПб., 2016. - 279 с.

2. Габриелян, А. А. История возникновения и развития концепции «мягкой силы». Институционализация «мягкой силы» / А. А. Габриелян // Журнал Российско-Армянского (Славянского) университета. - 2015. - № 5. - C. 122-131.

3. Долинский, А. В. Образовательные обмены в публичной дипломатии: российский и зарубежный опыт / А. В. Долинский // Вестник МГИМО (У).-2014. - № 2 (35). - С. 56-62.

4. Капицын, В. М. Семиотический аспект Soft power: политическая культура и символьная политика / В. М. Капицын // Мягкая сила. Мягкая власть. Междисциплинарный анализ: коллектив. моногр. / В. М. Алпатов [и др.] ; под ред. Е. Г. Борисовой. - М. : ФЛИНТА : Наука, 2015. - С. 11-13.

5. Ковалева, Д. М. Мягкая сила образования как средство установления культурных связей и достижения политических целей / Д. М. Ковалева // Россия и Восток: культурные связи в прошлом и настоящем : материалы Междунар. науч. конф. (IX Колосницынские чтения), 16-17 апр. 2014 года. Екатеринбург, 2014. - С. 33-36.

6. Концепция внешней политики Российской Федерации (утв. Указом Президента РФ от 30 ноября 2016 г. № 640). - Электрон. текстовые дан. - Ре- жим доступа: http://www.garant.ru/products/ipo/ prime/doc/71452062/ (дата обращения: 26.06.2018).Загл. с экрана.

7. Куприянова-Ашина, В. Интернационализация высшего образования: российские подходы / В. Куприянова-Ашина, Ж. Чанг // Международные процессы. - 2013. - Т. 11, № 2 (33). C. $87-88$.

8. Ланьшина, Т. А. «Мягкая сила» Германии: культура, образование, наука / Т. А. Ланьшина // Вестник международных организаций. - 2014. T. 9, № 2. - C. 28-58.

9. Лебедева, М. М. Высшее образование как потенциал «мягкой силы» России / М. М. Лебедева, Ж. Фор // Вестник МГИМО (У). - 2009. - № 6. C. 200-205.

10. Лебедева, М. М. «Мягкая сила» России в развитии интеграционных процессов на Евразийском пространстве / М. М. Лебедева, М. В. Харкевич // Вестник МГИМО (У). - 2014. - № 2. - С. 10-13.

11. Леонова, О. Г. Мягкая сила - ресурс внешней политики государства / О. Г. Леонова // Обозреватель. - 2013. - № 4. - С. 27-40.

12. Миронов, А. А. Идентификация деструктивных смыслов в противодействии «мягкой силы» / А. А. Миронов // Мягкая сила. Мягкая власть. Междисциплинарный анализ : коллектив. моногр. / В. М. Алпатов [и др.] ; под ред. Е. Г. Борисовой. М. : ФЛИНТА : Наука, 2015. - С. 29-31.

13. Панова, Е. П. Высшее образование как потенциал мягкой власти государства по специальности «Политика и политические науки» / Е. П. Панова // Вестник МГИМО (У). -2011. - № 2. - С. 157-161.

14. Першина, М. П. Образование как инструмент «мягкой силы» внешней политики Китая / М. П. Першина // Современные исследования социальных проблем : электрон. науч. журн. -2015 . № 4. - C. 4-27.-DOI: 10.12731/2218-7405-2015-4-27.

15. Радиков, И. В. «Мягкая сила» как современный атрибут великой державы / И. В. Радиков, Я. В. Лексютина // Мировая экономика и международные отношения. - 2012. - № 2. - С. 19-26.

16. Саямов, Ю. Н. Образование как «мягкая сила» для устойчивого развития / Ю. Н. Саямов // Межпредметное партнерство в реализации программы формирования экологической культуры, здорового и безопасного образа жизни : сб. междунар. конф. по образованию в интересах устойчивого развития. - М., 2014. - С. 15-18.

17. Суханова, Н. Е. «Мягкая сила» во внешней политике современной России / Н. Е. Суханова // Власть. - 2015. - № 12. - С. 79-84.

18. Торкунов, А. В. Образование как инструмент «мягкой силы» во внешней политике России / А. В. Торкунов // Вестник МГИМО (У). - 2012. № 4. - C. 86-89. 
19. Фоминых, А. «Мягкая мощь» обменных программ / А. Фоминых // Международные процессы. Цикл расхождений в мировой системе. 2008. - Т. 6, № 1 (16). - С. 76-80.

20. Цыганков, А. Всесильно, ибо верно? «Мягкая сила» и теория международных отношений / А. Цыганков // Россия в глобальной политике. -2013. - Т. 11, № 6. - С. 26-36.

21. Чепурина, М. А. Мягкая сила в глобальной политике: Болонские измерения / М. А. Чепурина // Вестник РУДН. Серия Политология. - 2014. № 1. - С. 96-103.

22. Шестова, Ю. О. Академическая мобильность студентов: основные подходы к определению понятия / Ю. О. Шестова, И. В. Рыжкова // Проблемы современного педагогического образования. 2017. - № 54 (8). - С. 153-159.

23. Широкова, Е. Г. «Мягкая сила/власть»: изменения составляющих / Е. Г. Широкова // Мягкая сила. Мягкая власть. Междисциплинарный анализ : коллектив. моногр. / В. М. Алпатов [и др.] ; под ред. Е. Г. Борисовой. - М. : ФЛИНТА : Наука, 2015. C. 24-25.

24. Aidarbek, A. Education and Soft Power: Analysis as an Instrument of Foreign Policy/A. Aidarbek // Procedia. Social and Behavioral Sciences. - 2014. Vol. 43. - P. 514-516.

25. Altback, P. G. The New Internationalism: Foreign Students and Scholars / P. G. Altback // Studies in Higher Education. - 1989. - Vol. 14, № 2. - P. 125-136.

26. Bertelsen, R. G. Private Universities, the State and Soft Power: the American University of Beirut and the Université Saint Joseph de Beyrouth / R. G. Bertelsen. - Electronic text data. - Mode of access: http://dpsa.dk/papers /American_French_ University_Soft_Power2.pdf(date of access: 28.06.2018). Title from screen.

27. Botonero, E. M. R. EU Higher Education as Soft Power in Neighbouring Countries: A Projection of Influence by Compelling Means / E. M. R. Botonero // ECPR General Conference Sciences Po Bordeaux 47 September 2013. - Bordeaux, 2013. - P. 1-28.

28. Ullah, Ch. S. China's soft power: changing the world perception / Ch. S. Ullah. -Monterey, 2015.-704 p.

29. King, K. China's Aid and Soft Power in Africa: The Case of Education and Training / K. King. Rochester: James Currey, 2013. - 238 p.

30. Chinese Soft Power and Its Implications for the United States. Competition and Cooperation in the Developing World. A Report of the CSIS Smart Power Initiative. - Washington : Center for Strategic and International Studies, 2009. - $137 \mathrm{p}$.

31. Deodato, E. Universities as actors and instruments in diplomacy. The academic soft power potential / E. Deodato, I. Borkowska // Valdai Papers. 2014. - № 8. - P. 6-7.
32. Cultural and Educational Exchange Programs.Electronic text data. - Mode of access: https://cm. usembassy.gov/education-culture/educationexchange-programs/ (date of access: 26.06. 2018). Title from screen.

33. Green, H. S. Top Global Soft Power? Japanese Higher Education and Foreign Policy Goals / H. S. Green // Toyohogaku. - 2016. - Vol. 60, № 1. - P. 89-101.

34. Jones, W. J. European Union Soft Power: Cultural Diplomacy \& Higher Education in Southeast Asia / W. J. Jones // Silpakorn University International Journal. - 2009-2010. - Vol. 9-10. - P. 42-70.

35. Knight, J. Moving from Soft Power to Knowledge Diplomacy / J. Knight // International higher education. - 2015. - № 8. - P. 8-9.

36. Knight, J. Higher education and diplomacy / J. Knight // The Diplomacy of Knowledge and Our Common Future. - Boston : Sense Publishers, 2014. P. 1-20.

37. Metzgar, E. T. Institutions of Higher Education as Public Diplomacy Tools / E. T. Metzgar // Journal of Studies in International Education. - 2015. - Vol. 20, № 3. - P. 223-241.

38. Carlos, R. S. Educational Cooperation as Soft Power: the Case of Brazil's Foreign Policy. ISA / R. S. Carlos // Global South Caucus. Singapore, 810 January 2015. - Singapore, 2015. - P. 3-4.

39. Nye, J. S. Soft Power / J. S. Nye // Foreign Policy. - Washington : Twentieth Anniversary, 1990. № $80 .-20$ p.

40. Nye, J. S. The Paradox of American Power: Why the World's Only Superpower Can't Go It Alone / J. S. Nye. - Oxford : Oxford University Press, 2002.$241 \mathrm{p}$.

41. Nye, J. S. Soft Power: the Means to Success in World Politics / J. S. Nye. - New York : Public Affairs, 2004. $-130 \mathrm{p}$.

42. Nye, J. S. Soft Power and Higher Education / J. S. Nye // The Coming of Post-Industrial Society: A Venture in Social Forecasting. - New York : Basic Books, 1999. - P. 41-70.

43. Nye, J. S. Soft Power. The Means To Success In World Politics / J. S. Nye. - New York : Public Affairs, 2005. $-130 \mathrm{p}$.

44. Polglase, G. Higher education as soft power in the Eastern Partnership: the case of Belarus / G. Polglase // Eastern Journal of European Studies. 2013. - Vol. 4, № 2. - P. 111-121.

45. Sheng-Kai, C. Higher education scholarships as a soft power tool: an analysis of its role in the EU and Singapore / C. Sheng-Kai // EUC Working Paper. 2015. - № 23. - P. 1-15.

46. Shields, R. Education / R. Shields, R. Edwards // Higher Education. Policy and the Global Competition Phenomenon. - New York: Palgrave Macmillan, 2010. $284 \mathrm{p}$. 
47. Soft power: теория, ресурсы, дискурс / под ред. О. Ф. Русаковой. - Екатеринбург : Издательский Дом «Дискурс-Пи», 2015. - 376 с.

48. Stetar, J. Soft Power Strategies: Competition and Cooperation in a Globalized System of Higher Education / J. Stetar, C. Coppla, L. Guo, N. Nabiyeva, B. Ismailov// Higher Education. Policy and the Global Competition Phenomenon. - New York : Palgrave Macmillan, 2010. - P. 191-204.

49. Tomusk, V. Pizza Bolognese a la Russe: The Promise and Peril of the Bologna Process in Russia / V. Tomusk // Creating the European Area of Higher Education: Voices from the Periphery. - Dordrecht : Springer, 2006. - P. 227-249.

50. Wojciuk, A. Education as a source and tool of soft power in international relations / A. Wojciuk, M. Michaiek // European Political Science. - 2015. Vol. 14 (3). - P. 1-20. - DOI: 10.1057/eps.2015.25.

51. Yang, R. China's Soft Power Projection in Higher Education / R. Yang // International Higher Education. - 2007. - Vol. 46. - P. 24-25.

52. Yang, R. Soft power and higher education: an examination of China's Confucius Institutes / R. Yang // Journal Globalisation, Societies and Education. 2010. - Vol. 8, iss. 2: The New Research Agenda in Critical Higher Education Studies. - P. 235-245.

53. Zhao, Litao. China's higher education as soft power? / Litao Zhao // EAI Background Brief. - 2011. № 659. - P. 1-15.

\section{REFERENCES}

1. Ageeva V.D. Rol instrumentov «myagkoy sily» vo vneshney politike Rossiyskoy Federatsii v kontekste globalizatsii: dis. ... kand. polit. nauk [The Role of Soft Power Tools in the Foreign Policy of the Russian Federation in the Context of Globalization. Cand. polit. sci. diss.]. Saint Petersburg, 2016. 279 p.

2. Gabrielyan A.A. Istoriya vozniknoveniya $i$ razvitiya kontseptsii «myagkoy sily». Institutsionalizatsiya «myagkoy sily» [History of Emergence and Development of the Conception of Soft Power. Institutionalization of "Soft Power"]. Zhurnal Rossiysko-Armyanskogo (Slavyanskogo) universiteta [Journal of the RussianArmenian (Slavic) University], 2015, no. 5, pp. 122-131.

3. Dolinskiy A.V. Obrazovatelnye obmeny v publichnoy diplomatii: rossiyskiy i zarubezhnyy opyt [Educational Exchanges in Public Diplomacy: Russian and Foreign Experience]. Vestnik MGIMO (U), 2014, no. 2 (35), pp. 56-62.

4. Kapitsyn V.M. Semioticheskiy aspekt Soft power: politicheskaya kultura i simvolnaya politika [Semiotic Aspect of Soft Power: Political Culture and Symbolical Policy]. Alpatov V.M., ed. Myagkaya sila. Myagkaya vlast. Mezhdistsiplinarnyy analiz: kollektiv. monogr. [Soft Power. Interdisciplinary Analysis. Collective Monograph]. Moscow, Flinta; Nauka Publ., 2015, pp.11-13.

5. Kovaleva D.M. Myagkaya sila obrazovaniya kak sredstvo ustanovleniya kulturnykh svyazey i dostizheniya politicheskikh tseley [Soft Power of Education as a Means of Establishing Cultural Ties and Achieving Political Goals]. Rossiya $i$ Vostok: kulturnye svyazi v proshlom $i$ nastoyashchem: materialy Mezhdunar. nauch. konf. (IX Kolosnitsynskie chteniya), 16-17 aprelya 2014 goda. Ekaterinburg, 2014, pp. 33-36.

6. Kontseptsiya vneshney politiki Rossiyskoy Federatsii (utv. Ukazom Prezidenta RF ot 30 noyabrya 2016 g. № 640) [Conception of Foreign Policy of the Russian Federation (Approved by Decree of the Russian President of November 30, 2016 No. 640)]. URL: http://www.garant.ru/products/ipo/ prime/doc/71452062/.

7. Kupriyanova-Ashina V., Chang Zh. Internatsionalizatsiya vysshego obrazovaniya: rossiyskie podkhody [Internationalization of Higher Education: Russian Approaches]. Mezhdunarodnye protsessy, 2013, vol. 11, no. 2 (33), pp. 87-88.

8. Lanshina T.A. «Myagkaya sila» Germanii: kultura, obrazovanie, nauka [Soft Power of Germany: Culture, Education, Science]. Vestnik mezhdunarodnykh organizatsiy, 2014, vol. 9, no. 2, pp. 28-58.

9. Lebedeva M.M., For Zh. Vysshee obrazovanie kak potentsial «myagkoy sily» Rossii [Higher Education as a Potential of Russia's Soft Power]. Vestnik MGIMO (U), 2009, no. 6, pp. 200-205.

10. Lebedeva M.M., Kharkevich M.V. «Myagkaya sila» Rossii v razvitii integratsionnykh protsessov na Evraziyskom prostranstve [Soft Power of Russia in Development of Integration Processes in the Euroasian Space]. Vestnik MGIMO (U), 2014, no. 2, pp. 10-13.

11. Leonova O.G. Myagkaya sila - resurs vneshney politiki gosudarstva [Soft Power - a Resource of Foreign Policy of the State]. Obozrevatel, 2013, no. 4, pp. 27-40.

12. Mironov A.A. Identifikatsiya destruktivnykh smyslov v protivodeystvii «myagkoy sily» [Identification of Destructive Meanings in the Counteraction of Soft Power]. Alpatov V.M., ed. Myagkaya sila. Myagkaya vlast. Mezhdistsiplinarnyy analiz: kollektiv. monogr. [Soft Power. Interdisciplinary Analysis. Collective Monograph]. Moscow, Flinta; Nauka Publ., 2015, pp. 29-31.

13. Panova E.P. Vysshee obrazovanie kak potentsial myagkoy vlasti gosudarstva po spetsialnosti «Politika i politicheskie nauki» [Higher Education as the Capacity of the Soft Power of the State in "Policy and Political Sciences"]. Vestnik MGIMO (U), 2011, iss. 2, pp. 157-161. 
14. Pershina M.P. Obrazovanie kak instrument «myagkoy sily» vneshney politiki Kitaya [Education as a Tool of Soft Power of the Foreign Policy of China]. Sovremennye issledovaniya sotsialnykh problem, 2015, no. 4, pp. 4-27. DOI: 10.12731/22187405-2015-4-27.

15. Radikov I.V., Leksyutina Ya.V. «Myagkaya sila» kak sovremennyy atribut velikoy derzhavy [Soft Power as a Modern Attribute of the Great Power]. Mirovaya ekonomika i mezhdunarodnye otnosheniya, 2012, no. 2, pp. 19-26.

16. Sayamov Yu.N. Obrazovanie kak «myagkaya sila» dlya ustoychivogo razvitiya [Education as a Soft Power for Sustainable Development]. Mezhpredmetnoe partnerstvo $v$ realizatsii programmy formirovaniya ekologicheskoy kultury, zdorovogo $i$ bezopasnogo obraza zhizni: sb. mezhdunar. konf. po obrazovaniyu $v$ interesakh ustoychivogo razvitiya. Moscow, 2014, pp. 15-18.

17. Sukhanova N.E. «Myagkaya sila» vo vneshney politike sovremennoy Rossii [Soft Power in the Foreign Policy of Modern Russia]. Vlast, 2015, no. 12 , pp. $79-84$.

18. Torkunov A.V. Obrazovanie kak instrument «myagkoy sily» vo vneshney politike Rossii [Education as a Tool of Soft Power in the Foreign Policy of Russia]. Vestnik MGIMO (U), 2012, no. 4, pp. 86-89.

19. Fominykh A. «Myagkaya moshch» obmennykh programm [Soft Power of Exchange Programs]. Mezhdunarodnye protsessy. Tsikl raskhozhdeniy $v$ mirovoy sisteme, 2008, vol. 6, no. 1 (16), pp. 76-80.

20. Tsygankov A. Vsesilno, ibo verno? «Myagkaya sila» i teoriya mezhdunarodnykh otnosheniy [It Is Omnipotent because It Is Right? Soft Power and the Theory of International Relations]. Rossiya v globalnoy politike, 2013, vol. 11, no. 6, pp. 26-36.

21. Chepurina M.A. Myagkaya sila v globalnoy politike: Bolonskie izmereniya [Soft Power in Global Policy: Bologna Measurements]. Vestnik RUDN. Seriya Politologiya, 2014, vol. 1, pp. 96-103.

22. Shestova Yu.O., Ryzhkova I.V. Akademicheskaya mobilnost studentov: osnovnye podkhody $\mathrm{k}$ opredeleniyu ponyatiya [Academic Mobility of Students: the Main Approaches to the Definition of the Concept]. Problemy sovremennogo pedagogicheskogo obrazovaniya, 2017, no. 54 (8), pp. 153-159.

23. Shirokova E.G. «Myagkaya sila/vlast»: izmeneniya sostavlyayushchikh [Soft Power: Changes of Components]. Alpatov V.M., ed. Myagkaya sila. Myagkaya vlast. Mezhdistsiplinarnyy analiz: kollektiv. monogr. [Soft Power. Interdisciplinary Analysis. Collective Monograph]. Moscow, Flinta; Nauka Publ., 2015, pp. 24-25.
24. AidarbekA. Education and Soft Power: Analysis as an Instrument of Foreign Policy. Procedia. Social and Behavioral Sciences, 2014, vol. 43, pp. 514-516.

25. Altback P.G. The New Internationalism: Foreign Students and Scholars. Studies in Higher Education, 1989, vol. 14, no. 2, pp. 125-136.

26. Bertelsen R.G. Private Universities, the State and Soft Power: the American University of Beirut and the Université Saint Joseph de Beyrouth. URL: http://dpsa.dk/papers /American_French_University Soft_Power2.pdf(accessed June 28, 2018).

27. Botonero E.M.R. EU Higher Education as Soft Power in Neighbouring Countries: A Projection of Influence by Compelling Means. ECPR General Conference Sciences (Bordeaux 4-7 September 2013). Bordeaux, 2013, pp. 1-28.

28. Ullah Ch.S. China's soft power: changing the world perception. Monterey, 2015. 704 p.

29. King K. China's Aid and Soft Power in Africa: The Case of Education and Training. Rochester, James Currey, 2013. $238 \mathrm{p}$.

30. Chinese Soft Power and Its Implications for the United States. Competition and Cooperation in the Developing World. A Report of the CSIS Smart Power Initiative. Washington, Center for Strategic and International Studies, 2009. 137 p.

31. Deodato E., Borkowska I. Universities as actors and instruments in diplomacy. The academic soft power potential. Valdai Papers, 2014, no. 8, pp. 6-7.

32. Cultural and Educational Exchange Programs. URL: https://cm.usembassy.gov/ education-culture/education-exchange-programs/ (accessed 26 June 2018).

33. Green H.S. Top Global Soft Power? Japanese Higher Education and Foreign Policy Goals. Toyohogaku, 2016, vol. 60, no. 1, pp. 89-101.

34. Jones W.J. European Union Soft Power: Cultural Diplomacy \& Higher Education in Southeast Asia. Silpakorn University International Journal, 2009-2010, vol. 9-10, pp. 42-70.

35. Knight J. Moving from Soft Power to Knowledge Diplomacy. International higher education, 2015, no. 8, pp. 8-9.

36. Knight J. Higher education and diplomacy. The Diplomacy of Knowledge and Our Common Future. Boston, Sense Publishers, 2014, pp. 1-20.

37. Metzgar E.T. Institutions of Higher Education as Public Diplomacy Tools. Journal of Studies in International Education, 2015, vol. 20, no. 3, pp. 223-241.

38. Carlos R.S. Educational Cooperation as Soft Power: the Case of Brazil's Foreign Policy. ISA. Global South Caucus. Singapore, 8-10 January 2015. Singapore, 2015, pp. 3-4.

39. Nye J.S. Soft Power. Foreign Policy. Washington, Twentieth Anniversary, 1990, no. 80.20 p. 
E.A. Антюхова. Образование как «мягкая сила» в современных политологических исследованиях

40. Nye J.S. The Paradox of American Power: Why the World's Only Superpower Can't Go It Alone. Oxford, Oxford University Press, 2002. 241 p.

41. Nye J.S. Soft Power: the Means to Success in World Politics. New York, Public Affairs, 2004. 130 p.

42. Nye J.S. Soft Power and Higher Education. The Coming of Post-Industrial Society: A Venture in Social Forecasting. New York, Basic Books, 1999, pp. 41-70.

43. Nye J.S. Soft Power. The Means To Success In World Politics. New York, Public Affairs, 2005. 130 p.

44. Polglase G. Higher education as soft power in the Eastern Partnership: the case of Belarus. Eastern Journal of European Studies, 2013, vol. 4, no. 2, pp. 111-121.

45. Sheng-Kai C. Higher education scholarships as a soft power tool: an analysis of its role in the EU and Singapore. EUC Working Paper, 2015, no. 23, pp. 1-15.

46. Shields R., Edwards R. Education. Higher Education. Policy and the Global Competition Phenomenon. New York, Palgrave Macmillan, 2010.284 p.

47. Rusakova O.F., ed. Soft power: theory, resources, discourse. Ekaterinburg, Diskurs-Pi Publ., 2015.376 p.
48. Stetar J., Coppla C., Guo L., Nabieva N., Ismailov B. Soft Power Strategies: Competition and Cooperation in a Globalized System of Higher Education. Higher Education. Policy and the Global Competition Phenomenon. New York, Palgrave Macmillan, 2010, pp. 191-204.

49. Tomusk V. Pizza Bolognese a la Russe: The Promise and Peril of the Bologna Process in Russia. Creating the European Area of Higher Education: Voices from the Periphery. Dordrecht, Springer, 2006, pp. 227-249.

50. Wojciuk A., Michaiek M. Education as a source and tool of soft power in international relations. European Political Science, 2015, vol. 14 (3), pp. 120. DOI: 10.1057/eps.2015.25.

51. Yang R. China's Soft Power Projection in Higher Education. International Higher Education, 2007, vol. 46, pp. 24-25.

52. Yang R. Soft power and higher education: an examination of China's Confucius Institutes. Journal of Globalisation, Societies and Education, 2010, vol. 8, iss. 2: The New Research Agenda in Critical Higher Education Studies, pp. 235-245.

53. Zhao Litao. China's higher education as soft power? EAI Background Brief, 2011, no. 659, pp. 1-15.

\section{Information about the Author}

Ekaterina A. Antyukhova, Candidate of Sciences (Politics), Senior Lecturer, Department of Comparative Political Science, Moscow State Institute of International Relations, Ministry of Foreign Affairs of Russia, Prosp.Vernadskogo, 76, 119454 Moscow, Russian Federation, e.ant1507@yandex.ru, https://orcid.org/0000-0003-0860-4792

\section{Информация об авторе}

Екатерина Андреевна Антюхова, кандидат политических наук, старший преподаватель, кафедра сравнительной политологии, Московский государственный институт международных отношений (У) МИД РФ, просп. Вернандского, 76, 119454 г. Москва, Российская Федерация, e.ant1507@yandex.ru, https://orcid.org/0000-0003-0860-4792 